\title{
Multi-scale configurational approach to the design of public open spaces after urban disasters
}

\author{
Chiara Chioni $^{1 *}{ }^{[0000-0002-8296-3091]}$, Camilla Pezzica ${ }^{1,2}$ [0000-0002-0512-7591], Valerio Cutini ${ }^{1 \mathrm{c}}$ \\ ${ }^{[0000-0003-4065-6226]}$, Clarice Bleil de Souza ${ }^{2 b}{ }^{[0000-0001-7823-1202]}$, and Simone Rusci ${ }^{1 d}[0000-$ \\ 0003-2806-6661] \\ ${ }^{1}$ D.E.S.Te.C., University of Pisa, 56122 Pisa, Italy \\ ${ }^{2}$ Welsh School of Architecture, Cardiff University, CF10 3NB Cardiff, UK \\ ${ }^{1 *} \mathrm{C}$. chioni@studenti.unipi.it, ${ }^{1,2 p e z z i c a c}{ }^{2}$ cardiff.ac.uk, \\ 1cvalerio.cutini@ing.unipi.it, 2bbleildesouzacecardiff.ac.uk, \\ ldsimone.rusci@unipi.it
}

\begin{abstract}
Housing shortage after urban disasters is often approached by governments and humanitarian organisations by building prefabricated houses that, during the transition between emergency and reconstruction, materialize the paradox of the permanency of a temporary situation. The events that followed the 2016-2017 seismic crisis in Central Italy do not seem to be an exception: in absence of permanent houses, the displaced people have been accommodated in S.A.E. (housing emergency solutions) within temporary villages of heterogeneous social, spatial and environmental qualities. With the aim to explore and improve way-finding in the disaster-impacted settlements as well as accessibility and sociability of the temporary sites' public open spaces, this paper proposes a human-centred design research approach in performance-based housing recovery planning and design decision-making, combining principles and methods from Space Syntax and Public Life Studies. This research demonstrates how to coordinate different digital analysis and design tools by illustrating their application in an urban regeneration project for Borgol, a temporary housing settlement in the municipality of Arquata del Tronto. Specifically, the paper shows how a multi-scale and multidimensional study of the site allowed identifying the ideal location for a new public square and subsequently guided the design process towards the initial design goals' achievement.
\end{abstract}

Keywords: Temporary Housing, Disaster Recovery, Central Italy Earthquake, Space Syntax, Design Decision-Making.

\section{Introduction}

\subsection{Background}

Housing assistance after urban disasters is often delivered to the affected population in two or more of the following stages: emergency shelter, temporary shelter, temporary housing, and permanent housing [1]. This paper focuses on Temporary Housing 
(TH), which is a particularly controversial stage of post-disaster housing recovery because, despite providing dignity and privacy to the affected population while permanent homes are built [2], it often materialises the paradox of the immobility of a temporary situation becoming de facto permanent [3]. As a matter of fact, in the past TH settlements have rarely been completely dismantled when reaching the end of their functional life at the completion of the reconstruction works, partially because of their physical constitution and extension, connected services and difficulties in restoring the original land uses as well as their cost. Table 1, which includes data from the latest eleven most destructive earthquake disasters in Italy, shows that the actual lifespan of TH sites often far exceeds the theoretical reference time of 5 years. Furthermore, among other issues, the emergence of hybrid urban realities with uncertain identities from the assemblage of temporary housing settlements and reconstructed cities in Italy, has evidenced the shortcomings of implementing technocratic practices focused on quick results and lacking planning foresight $[4,5]$.

Table 1. Data of the most serious earthquakes that have struck Italy from 1900 to date $^{1}$.

\begin{tabular}{|c|c|c|c|c|c|}
\hline Event & $\begin{array}{c}\text { Magnitude } \\
(\mathrm{Mw})\end{array}$ & Deaths & Homeless & $\begin{array}{l}\text { Permanence } \\
\text { in TH (years) }\end{array}$ & $\begin{array}{c}\text { Reconstruction } \\
\text { time (years) }\end{array}$ \\
\hline 1908 Messina & 7.1 & $120 \mathrm{k}$ & - & $30-110$ & - \\
\hline 1915 Marsica & 7.0 & 33,522 & $15 \mathrm{k}$ & 100 & - \\
\hline $\begin{array}{l}1920 \text { Garfagnana- } \\
\text { Lunigiana }\end{array}$ & 6.5 & 171 & - & 4 & 10 \\
\hline 1968 Belice & 6.3 & 296 & $57 \mathrm{k}$ & $12-20$ & $\begin{array}{c}60^{*} \\
(2028)\end{array}$ \\
\hline 1976 Friuli & 6.5 & 965 & $189 \mathrm{k}$ & $8-10$ & 10 \\
\hline 1980 Irpinia & 6.9 & 2,735 & $400 \mathrm{k}$ & $15-37$ & $\begin{array}{c}43 * \\
(2023)\end{array}$ \\
\hline $\begin{array}{l}1997 \text { Umbria- } \\
\text { Marche }\end{array}$ & 6 & 11 & $25 \mathrm{k}$ & $5-20$ & $\begin{array}{c}27 * \\
(2024)\end{array}$ \\
\hline 2002 Molise & 5.7 & 30 & $10 \mathrm{k}$ & $6-14$ & $\begin{array}{c}21 * \\
(2023)\end{array}$ \\
\hline 2009 L'Aquila & 5.9 & 309 & $70 \mathrm{k}$ & $\begin{array}{l}\text { on going } \\
\text { (so far 11) }\end{array}$ & $\begin{array}{c}14 * \\
(2023)\end{array}$ \\
\hline 2012 Emilia & 5.9 & 26 & $15 \mathrm{k}$ & $3-5$ & on going \\
\hline 2016 Central Italy & 6.5 & 299 & $50 \mathrm{k}$ & $\begin{array}{l}\text { on going } \\
\text { (so far 4) }\end{array}$ & on going \\
\hline
\end{tabular}

1 The star $(*)$ indicates a forecast of the reconstruction time based on Ruggiero [3]. 
According to Scamporrino [6] a disaster and a lengthy recovery generate three new cities that co-exist in parallel during the reconstruction process: (i) the historical one, destroyed and inaccessible; (ii) the present one, in transition and (iii) the future one, in transformation. Currently, design and planning activities after urban disasters seem to follow the same tripartite structure as the following three proposals tend to be separately developed: (i) one for the reconstruction of the destroyed area of the city; (ii) one for the temporary city and finally (iii) another for the future city as a whole. Within this framework, public spaces assume different meanings in the three cities, because the community relates to those in a different way [6]. In the destroyed city, public open spaces have an intelligible morphology, are formally determined and are known by the community. In the temporary city, such spaces are improvised, interstitial and considered precarious. In the transformed city they are new and unfamiliar.

Nonetheless, under certain conditions another possibility exists, which involves holistically designing and planning the transitional city by triggering and supporting the transformation of both the destroyed and the temporary cities into the future permanent one. Because the main objective of disaster recovery plans is to "build back better" [7, 8], a promising strategy to foster this aim seems to be the careful (re)design of the public open space, which can work as a key reference point for local communities, hosting key social functions which define the identity of the impacted cities and territory, thus supporting the planned recovery pathway towards more sustainable urban futures. While, to date, the design of public open spaces after disasters is often concerned almost exclusively with the reconstruction of those in the destroyed city or with the proposition of new spaces for the future city - following the principle of "where it was as it was" and by proposing the realization of new areas or the relocation of previous ones - the temporary city is often overlooked. This is a missed opportunity to design for the present as well as for the future while preserving the values from the past, local community bonds as well as positive socio-economic relations. Dealing with temporariness and time as key design parameters in drafting of recovery and reconstruction plans, architects and urban planners can succeed in guiding the reconstruction of a new city whose public space supports the continuous reproduction of the key material and immaterial components of the old one [9].

\subsection{Aims and objectives}

This paper seeks to explore and test novel ways in which architects and urban planners can help supporting the transition from recovery to reconstruction. To this end, it suggests coordinating various types of analyses in an urban design process whose ultimate goal is to understand and improve the quality of the open public space in the temporary settlements and encourage its ownership and enjoyment by the displaced community. Specifically, this paper will present a Design Research study [10] exploring the advantages of adopting a data-driven approach to the design of a public square, which provides opportunities for social gathering and thus improves urban and community resilience [11]. The underlying hypothesis is that the solution of such a complex urban design problem would benefit from prior and parallel research and 
from the use of computational methods and tools in designing for socio-spatial performance.

\subsection{The case of Central Italy}

This paper applies the proposed method to the case of the latest Italian earthquake in which this multi-staged housing recovery approach was implemented, i.e. the 20162017 Central Italy earthquake. There, the disaster affected approximately 600,000 people in 10 different districts (province), and 138 municipalities (comuni) of four Central Italy regions, thus creating a new disaster geography extending for a total of $8000 \mathrm{~km} 2$. In this territory about 50,000 homeless people required housing assistance and were accommodated by resorting to different solutions, including prefabricated housing structures, hotels, rural emergency modules or containers, municipal facilities, or cash grants for private housing rental. Among these internally displaced people, 7782 requested to be housed in prefabricated temporary houses called S.A.E (housing emergency solutions), which were assembled in 228 sites built in the proximity of the disaster-impacted towns, in locations that were deemed suitable by both local municipalities and regional authorities [12], (see Fig. 1).

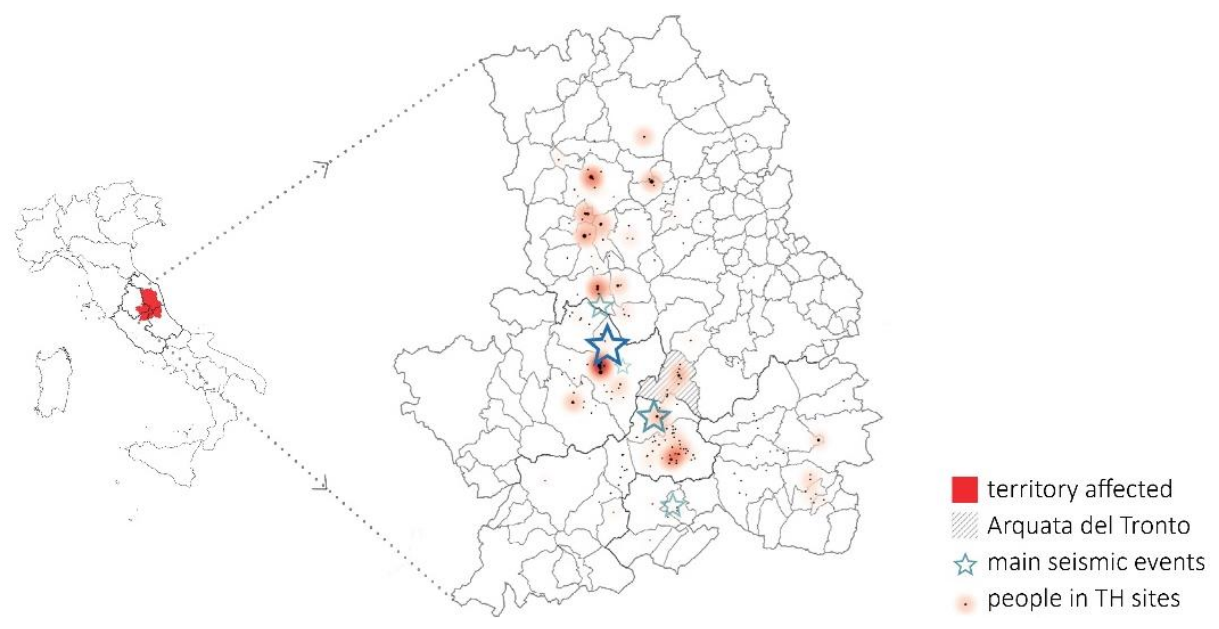

Fig. 1. Location of the disaster affected area in central Italy (with Arquata del Tronto pinpointed in grey) and heat map of the number of people hosted in the TH sites. The epicentres of the 2016-2017 earthquakes are marked with stars proportional to their magnitude.

To date, the physical and administrative difficulties and consequent delays of the permanent housing reconstruction process [13], have constrained local people - a predominantly elderly population - to live for an extended period of time in the temporary S.A.E. settlements with social, spatial and environmental urban qualities that can hardly match the needs of the affected communities, as these were not designed for lasting. Furthermore, a twofold mismatch is registered between: (i) temporary housing offer and demand due to dynamic needs fluctuations; (ii) use of temporary 
and permanent housing standards due to uncertainty in relation to the actual dwellings' life span [3]. Arguably, this involves a risk that further negative impacts will follow a short-sighted humanitarian response that is not holistic enough, i.e. not considerate that disaster recovery is a process that involves rebuilding the historical, cultural, social and symbolic identity of a place by restoring collective values also via the design of suitable public open spaces that materialize the social pact upon which a community is founded.

\subsection{Borgo1 TH site in Arquata del Tronto}

To better research and illustrate potential benefits and limitations of the proposed design approach, an applied investigation is conducted in a real case: a temporary housing site in Arquata del Tronto (district of Ascoli Piceno, in Marche Region, Ita1y). This was identified in [14] as a particularly relevant case, following a comparative network analysis of the post-disaster configurations of 4 different municipalities impacted by the 2016-2017 Central Italy earthquake. The temporary village is that of Borgol, which is the largest of 7 newly built temporary housing settlements around the destroyed urban historic centre of Arquata del Tronto and the closest to it (see Fig. 2).

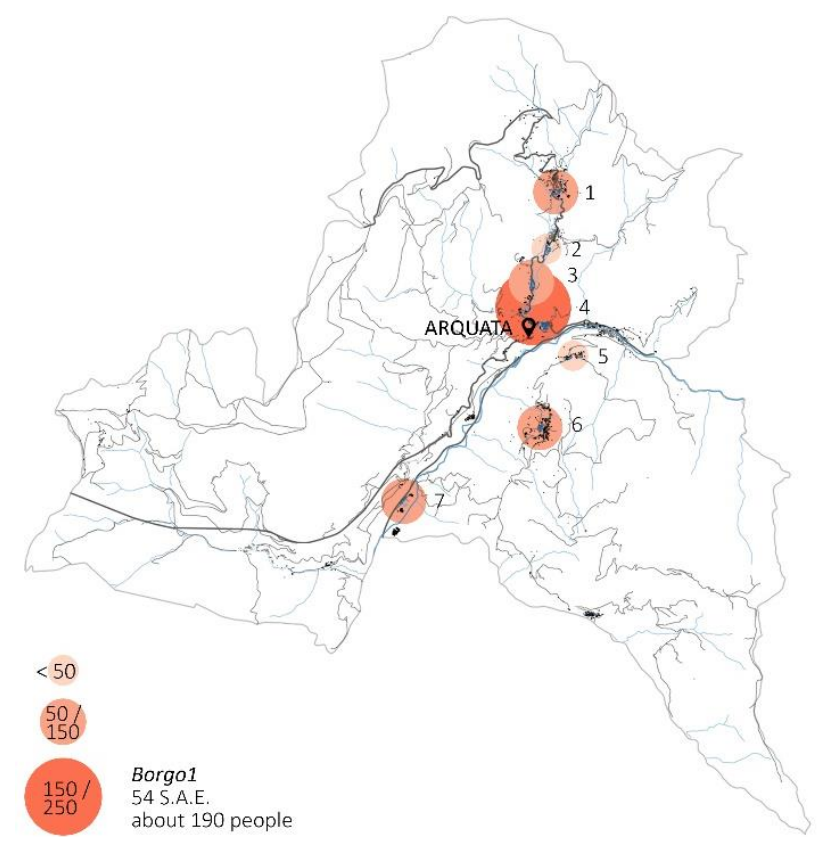

Fig. 2. Post-earthquake "temporary" demography in the municipality of Arquata del Tronto (with pinpointed historic centre). The TH sites are numbered: (1) Pretare, (2) Piedilama, (3) Borgo2, (4) Borgo1, (5) Faete, (6) Spelonga, and (7) Pescara. 
In this specific case, based on the official planning documents, recent investments, and the current situation, it is legitimate to imagine a future scenario in which the $\mathrm{TH}$ site will not be returned to its previous land use. Even the S.A.E. housing units are unlikely to be completely dismantled in the future, due to the permanent nature of their foundation systems (reinforced concrete slabs) and connected services. Thus, the site is likely to remain in use in the longer-term, possibly hosting other people when the local residents will return to their permanent homes and undergoing (or not) adaptions in terms of function, configuration and/or built density. Indeed, even when their intended "temporary" use ends, the site can be considered a resource for which new plans should be made. As of today, its final identity is not fully determined, but opportunities exist for it to be shaped.

\section{$2 \quad$ Materials and methods}

To better deal with the transitional city and improve the performance of outdoor public space in terms of wayfinding, spatial accessibility as well as sociability the authors perform a multidimensional analysis combining techniques from Space Syntax and Public Life Studies. First, an analysis of the configurational qualities of Borgol TH site and its surrounding areas are undertaken, identifying present and future opportunity spaces for public use. After identifying a suitable place for the creation of a public open space, a design research experiment is undertaken, aimed at enhancing the socio-spatial characteristics of the transitioning residential environment of Borgol. The resulting urban design proposal does not have the ambition to replace what has been lost, but rather seeks to facilitate the passage from the past to the future, acting as an interface between absence and new presence (see Fig. 3).

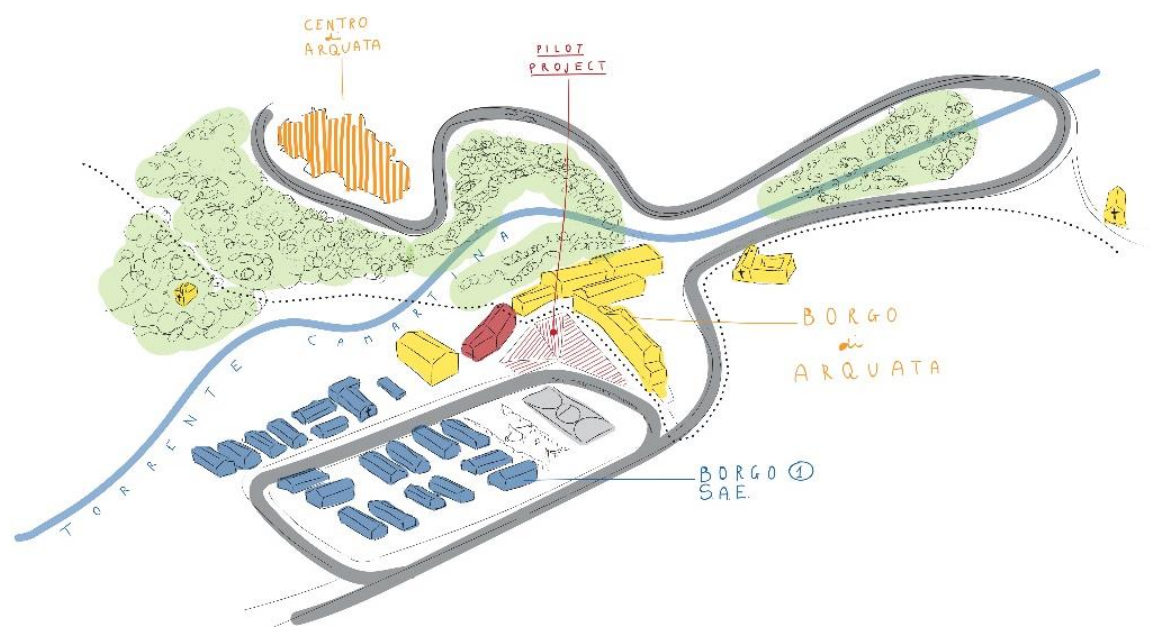

Fig. 3. Contextualization of the project. 
Assuming the articulation of the urban grid as a key driver for urban systems' dynamics [15], this paper adopts a configurational approach to guide and audit design proposals related to the provision of mid-term housing assistance after disasters [16, 17]. Space Syntax techniques are exploited as part of a multi-scale analysis to: (i) understand the diachronic development of Arquata del Tronto and evaluate the impact of the new emergency settlements on its urban configuration (urban scale); (ii) grasp the relational characteristics of the temporary site of Borgol to orient urban design (neighbourhood scale). Therefore, the authors analyse the pre-earthquake (T1), postearthquake (T2), current (T3) and hypothetical future (T4) road network configurations of Arquata del Tronto as well as the area of Borgol and its immediate context to identify a suitable space to design a new square (T5), with adequate qualities to be a successful and socially oriented public place. This research complement results and partially assesses the reliability of Space Syntax analysis models by using empirical evidence from a Public Life study [18]. The design decision-making process including how the analysis is used to iteratively set and assess design aims in a reflective manner is illustrated in sections 2.1 and 2.2.

\subsection{Space Syntax analysis as an urban design method}

In the past two decades, Space Syntax has proved to be a valuable support tool in the design of many successful public open spaces among which Trafalgar Square, Nottingham Old Market Square and Woolwich Squares [19]. Karimi [20] shows that the Space Syntax methodology can be effectively used as a formal framework in urban design, meanly because:

- It is a spatial analytical approach and thus suitable for design.

- It can create a direct link between space and people (or users).

- It can deal with different spatial scales.

- It allows investigating an urban or architectural system as a whole or just in parts.

Space Syntax analysis engages with the design process by supporting the negotiation between design problem and solution through continuous iterations of analysis, synthesis, and evaluation activities [21]. When adopting this approach, a series of configurational analyses informs the design process from the outset by detecting the problems and latent potentials of a site, which refines both the brief and scope of a design project. In this sense, the analysis of the existing situation enhances the general understanding of the design context and can inspire the formation of new design ideas. When repeated to test a design hypothesis at a later stage, the analysis enhances the assessment of proposals by adding objectivity to it and thus forming a key element of the conjecture-test design cycle. In fact, when a possible design solution emerges from the negotiation with the previously identified issues, the baseline analysis can be used to formally gauge improvements in terms of socio-spatial and functional performance. This cycle can be applied at different scales (e.g. urban and micro-urban or global and local).

This paper coordinates various analysis methods: Angular Segment Analysis [22], Visibility Graph Analysis [23] and Agent-based analysis [24]. The first informs the 
"natural" distribution of traffic and pedestrian flows across the city, expressed by the Choice index (or NACH), and towards the urban centre, expressed by the Integration index (or NAIN). The second maps in two dimensions some relational and visual qualities of public open spaces identified by Cutini [25] and Guerreiro [26] as key spatial conditions for public squares to work as effective meeting and interaction places by using the following configurational indices: Integration Index, Clustering Coefficient, Connectivity, Visual Control. The agent-based analysis simulates navigational performance and pedestrian flow intensity through a Gate Count. According to Pezzica et al. [18] selecting a few suitable variables can help the designer focusing on the most significant properties of a space, while increasing control over design outputs and simplifying project evaluation.

\subsection{Public life studies as a design method}

Public Life Studies investigate urbanity by observing the way public space is used in cities and foster the adoption of a people-centric perspective in urban research and design. This field of study became increasingly systematic with the key contributions of Gehl [27] and Whyte [28], whose works are based on first-hand observations of public life in Scandinavia and in New York, respectively. According to them, what attracts the attention and interest of those who inhabit public open spaces in cities are other people and human activities in general. Therefore, successful social spaces tend to be in the proximity of paths and roads hosting pedestrian flows because this enables people to see each other while carrying out other activities.

Gehl [27] adopts a probabilistic approach to the relationship between design and human activities and argues that, through design and within certain limits (i.e. regional, climatic and societal constraints), it is possible to influence the amount of people who use public spaces, how long individual activities will last and guess which activities people are more likely to engage with. According to him, when public spaces are of a poor quality, only strictly necessary activities tend to occur (e.g. going to school or to work, shopping or waiting for a bus). Necessary activities usually take place with approximately the same frequency - although people may choose to spend longer doing them - when public spaces are of a higher quality, but a wider range of optional (i.e. taking a walk to get a breath of fresh air, stopping for a coffee in a street café, people-watching) and social (i.e. simply seeing and hearing other people) activities also begin to occur. Furthermore, Whyte [28] highlights that successful public spaces usually possess more of the following features:

- A good location, preferably on a busy route, being both physically and visually accessible.

- A permeable threshold with the streets, without being cut off from them with railings or walls isolating it and reducing its use by people.

- Are levelled (or almost) with the pavement.

- Have places to sit, either explicit (benches, seats, etc.) and integral (steps, low walls, etc.). 
- Have moveable seats, enabling choice and a better communication of individual characters and personalities.

Using field Public Life Studies observations techniques [27], Space Syntax analysis models can be validated [18] and used to simulate "what if" scenarios, while relevant guidelines for encouraging space appropriation by the public [28] can be useful to set further design choices.

\section{Results and discussion}

\subsection{Urban scale analysis}

In Figures 4 and 5, the results of the ASA configurational analysis of Arquata del Tronto's street network are illustrated, with respect to Arquata and Borgol, at the four points in time mentioned in section 2 (T1-T4) to disclose differences in terms of short and long-term impact of TH plans in the urban spatial functioning. The proposal for T5 is developed by reflecting on these results. However, T5 it is not analysed at this scale, because the design intentionally does not introduce a significant variation in the street network configuration.

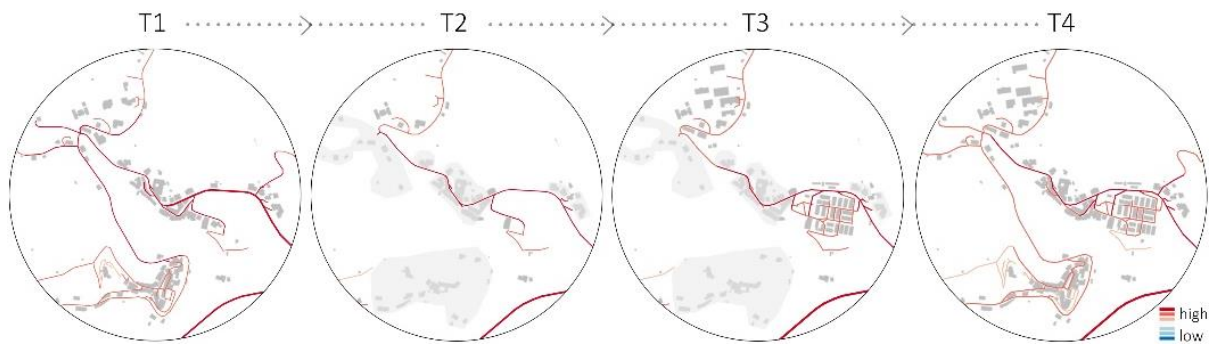

Fig. 4. Zooms on Arquata and Borgol of Arquata del Tronto's ASA analysis (T1-T4): NAIN index with the integration core highlighted (the thicker lines).

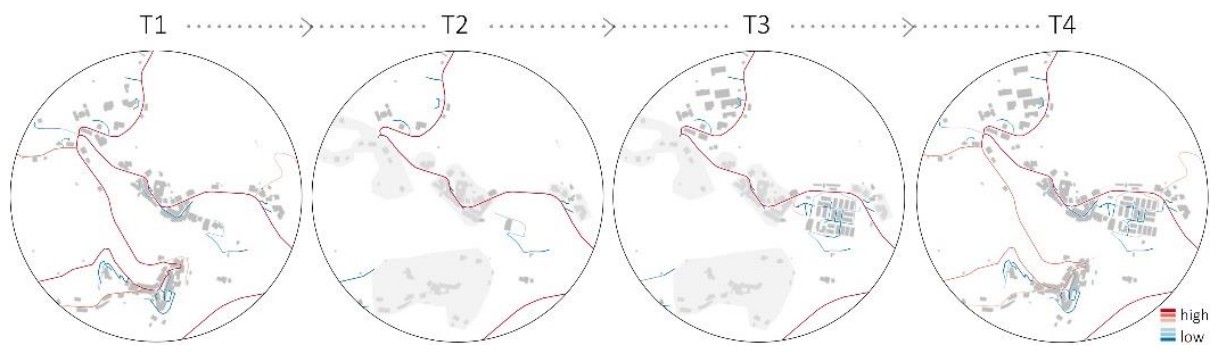

Fig. 5. Zooms on Arquata and Borgol of Arquata del Tronto's ASA analysis (T1-T4): NACH index.

The map highlights that the municipality of Arquata del Tronto has had a linear development along its main access roads, which is reflected by the highly polarised 
distributions of NAIN and NACH (T1). When the earthquake destroyed Arquata's historic centre, causing its closure for safety and reconstruction purposes (T2), the centrality values of the areas surrounding the original urban core decreased. This trend is further reinforced by the location of the TH sites during the recovery phase (T3). The analysis shows that in the T4 conservative reconstruction hypothesis, Arquata del Tronto will be significantly affected by the presence of the TH sites, because the old centre will remain a mere repository of a local level of centrality while the TH site of Borgol will emerge as the new actual global centre, acquiring higher spatial accessibility, economic value and social desirability and thus competing with the reconstructed old town centre. In fact, the distribution of NAIN shows that a continued presence of the TH sites after the reconstruction is likely to redefine the spatial accessibility pattern of Arquata, creating the conditions for local economic activities to move out of the historic centre; which is likely to trigger a process of urban decentralisation [4]. Indeed, according to the analysis at T4, the street running along the northern limit of Borgol will result the most central and accessible.

\subsection{Neighbourhood scale analysis}

Further analyses at the neighbourhood scale have been conducted around Borgol, which assumes a key social role, justifying an effort to strengthen its relational functions through urban design (see section 3.4). A VGA is used to investigate properties that are closely related to manifestations of spatial perception, such as wayfinding, movement, and space use. Here, the configurational metrics used are: (i) Integration Index (a proxy for spatial accessibility); (ii) Connectivity (visual capacity); (iii) Clustering Coefficient (identifies convex spatial pockets allowing a comfortable social interaction); (iv) Visual Control (identifies spaces where people tend to make navigation decisions). Indeed, the potentiality of an urban place to favour interaction depends on its level of centrality, the richness of its visual connections, its capacity to visually enclose people as if they were in an outdoor room, which make a square a "place of glances" [29].

In Figure 6 the properties of space related to spatial navigation and visual perception have been analysed at four points in time, namely T1, T3, T4 and T5. The analysis of T2 would have been relevant to decide the location and layout of the TH site, which in this case is already known and fixed. Specifically, the figure shows the multitemporal distribution of two key VGA indices, namely the Integration index and the Clustering Coefficient, which uses the same colour gradient of the urban scale analysis. 


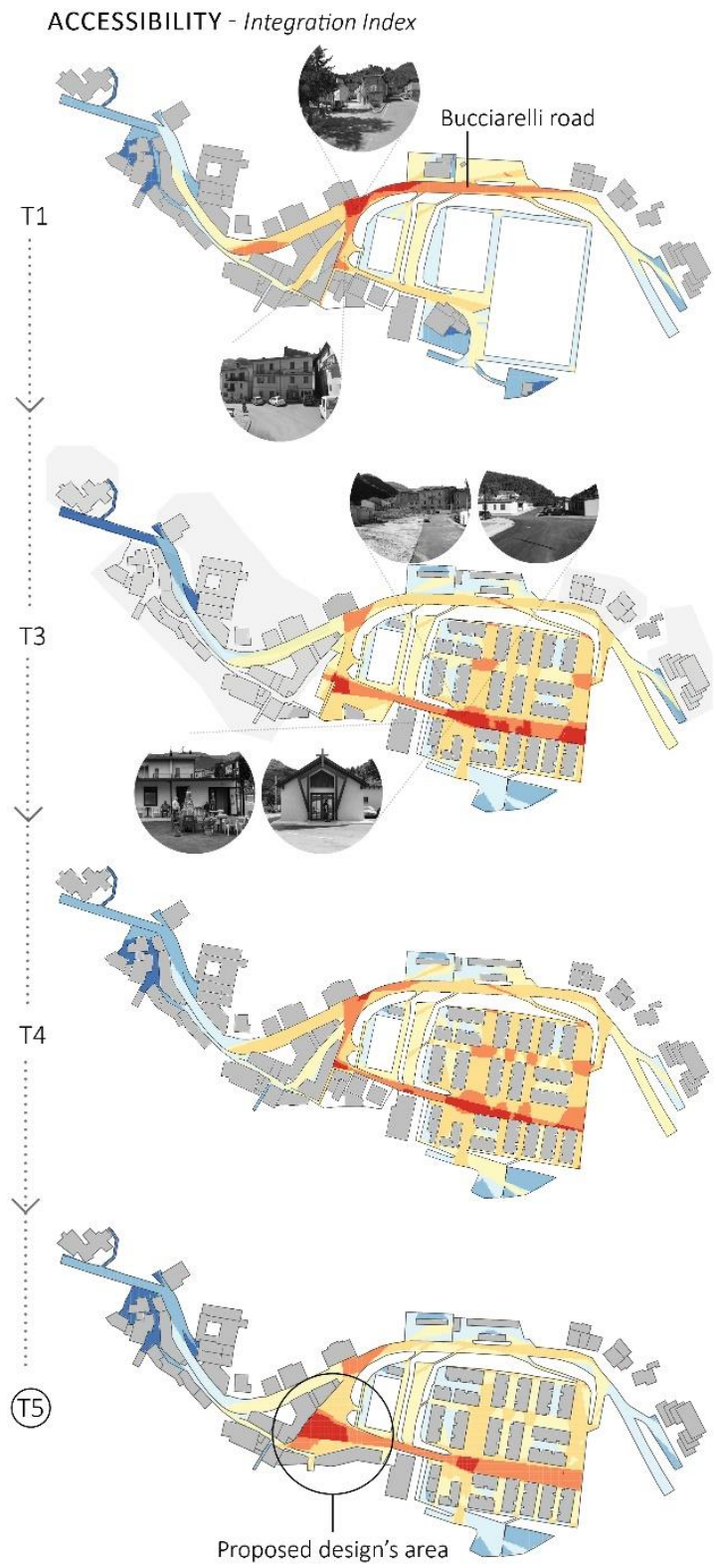

INTERACTION - Clustering Coefficient
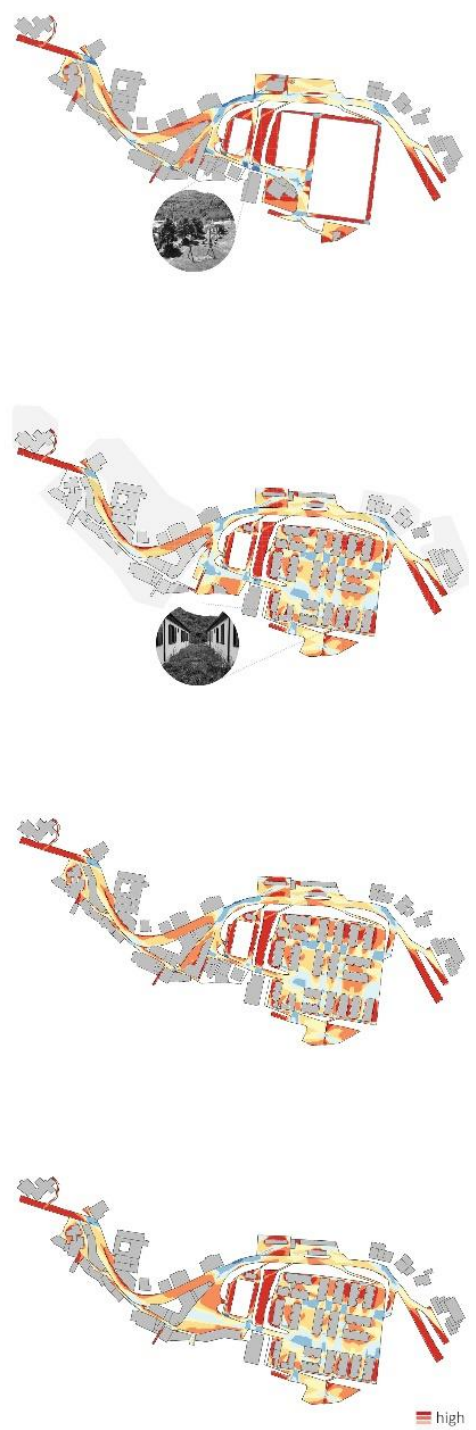

Fig. 6. Borgol's VGA analysis (T1, T3, T4 and T5): Integration index (left) and Clustering coefficient (right, miniaturized). The photos help to understand (and confirm) the VGA results.

After the construction of the TH settlement (T3), the spatial permeability of the area hosting the former playground changed dramatically: several new open spaces - from 
the little pockets between the $\mathrm{TH}$ units to the large esplanade resulting from the demolition of earthquake-damaged buildings on the south-west corner of the site sprang up. Notably, two perpendicular axes emerged with a high value of centrality/accessibility (corresponding to a high value of the Integration Index), with the horizontal one crossing the temporary village from side to side. Even after the end of the reconstruction (T4), if no other changes apply, the new road axes will maintain a high local configurational importance.

The presence of the large empty space resulting from the demolition of the group of damaged houses between the historic hamlet of Borgo and the temporary village of Borgol, offer a unique opportunity to regenerate the site, by better sewing up the old and the new (T5). The high values of the configurational indices emerging from the analysis indicate the potential of this urban void to work as an effective public space, which represents an urban alternative to the existing precariousness.

The analysis of the final design hypothesis at T5 shows the benefits of implementing the regenerative design proposal, whose development process is described in detail in the next two sections. In particular, the level of local accessibility and centrality increases, sign of the centralization of the stationary activities, which are the key for achieving an active occupation of the entire square's area.

\subsection{Model validation}

In order to carry out a qualitative assessment of the VGA analysis model and collect complementary information useful to inform an urban design (T5), some empirical evidence was collected during a two-days field visit in September 2019, via: (i) a photographic recording with written annotations, following a direct observation of dwellers interacting with their surrounding space; (ii) a short survey, which was circulated among the residents of Borgol to get their views about the performance of their environment in relation to their wishes and needs. Survey respondents were 11, which accounts for the $20 \%$ of the 54 housing units in the site. Direct observations confirmed analysis results in relation to pedestrian and vehicular flows, which concentrated in Bucciarelli road and then in the two internal axes. A few people were occupying the outdoor spaces and the majority was found gathering at the only local bar. When asked in the survey, $59 \%$ of the respondents declared to be dissatisfied or very dissatisfied with aggregation spaces in the area and lamented the "lack of a meeting place" and that of "a multipurpose center".

When tasked with marking on a map of the area where do they meet with other people, they pinpointed a few locations, circled in Figure 7, which match the results of VGA analysis at T3 (see Fig. 6) and specifically the distribution of Visual Control.

The good correspondence observed between the results obtained from the model at T3 and the real social attractiveness of the space, suggests the opportunity of relying on its predictive capacity for further analysis and design purposes. Project choices can then be weighted and iteratively refined according to the predicted configurational characteristics of the space so as to influence the expected behavior of users. 
GATHERING - Visual Control

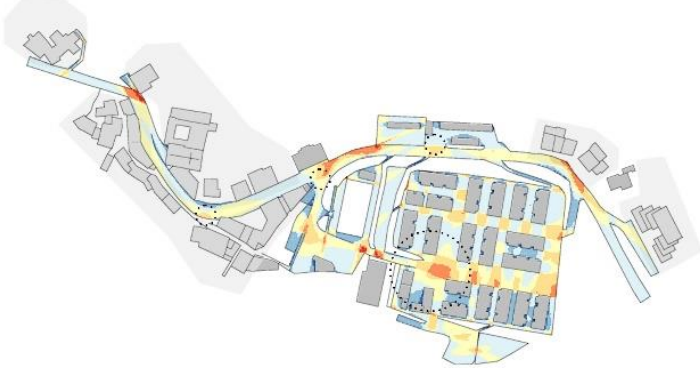

Fig. 7. Borgol's VGA analysis (T3): Visual Control. Indication (circles) of the most used meeting points according to the survey.

\subsection{The project}

The proposed design aligns with the Municipality's declared priorities which include: the return of the residents to their homes; the socio-economic revitalization of the territory and the morphological and functional redevelopment of the urban system also through the redefinition of public open spaces.

The strategic framework chosen for the proposed regenerative intervention is divided in three phases with the following objectives:

- A short-term phase oriented at recovering the public and the pedestrian mobility within the municipality, between the historic hamlets and the $\mathrm{TH}$ areas.

- A medium-term phase ('transitional city project') involving the design of an open public space, whose boundary is defined by the construction of an anti-seismic structure meant to rehouse part of the displaced residents and permanently relocate the temporary facilities located in the TH settlement.

- A long-term phase - corresponding to a possible T6, here not explored - in which the TH site is redesigned while ensuring availability of resources to the Civil Protection Department (in view of possible future events) by transforming the $\mathrm{TH}$ units into something else such as (i) an holiday camp, (ii) a second-homes village or (iii) a new location for the destroyed municipal hamlet of Pescara del Tronto.

The proposal for T5 specifically addresses the short-term and the "transitional city project' and is built on the outputs of the ASA and VGA analyses. The former (see 3.1, ASA analysis at urban scale, particularly at T3), allowed identifying the most accessible site to host and favour the project of a post-disaster open public space. The latter helped defining the morphology of the square and so that it maximises its social functionality (see 3.2, VGA analysis at the neighbourhood scale, T5).

To this end, an agent analysis (see Fig. 10) was used to 'predict' in several simulated scenarios, the likely behaviour of the local users, assuming that their behaviour in a new space would approximate that of the agents during a random walk. 
The design concept is illustrated in all its multifaceted components in Figure 8. The first step of the underlying design process was the definition of the square's boundary (see Fig. 8.1), as enclosure capacity is one of the main physical property that a square must have to work properly [30]. The southern edge is closed by introducing a new mix-use building that, following the course of the slope, reconnects the fronts of those existing buildings, which are still standing. Conversely, the front adjacent to the vertical road is left open because the street is part of the social space and cutting it out would reduce the use of the square [28]. Then, the vertical connections between the different topographic levels were re-designed in a way that the square does not present physical/visual obstacles according to the principle that the presence of people coupled with weak or no barriers creates a good public space [27]. Figure 8.2 shows that four triangular paved "slices" are inclined in order to overcome the height difference between the various topography levels. This way people in the lower spaces provide the show to the people sitting or walking above and, as a result, the orography of the site will resemble that of an amphitheatre, from which you can observe both the S.A.E. area, down the street, and the historic front of the buildings on the top of the slope (see Fig. 8.3).
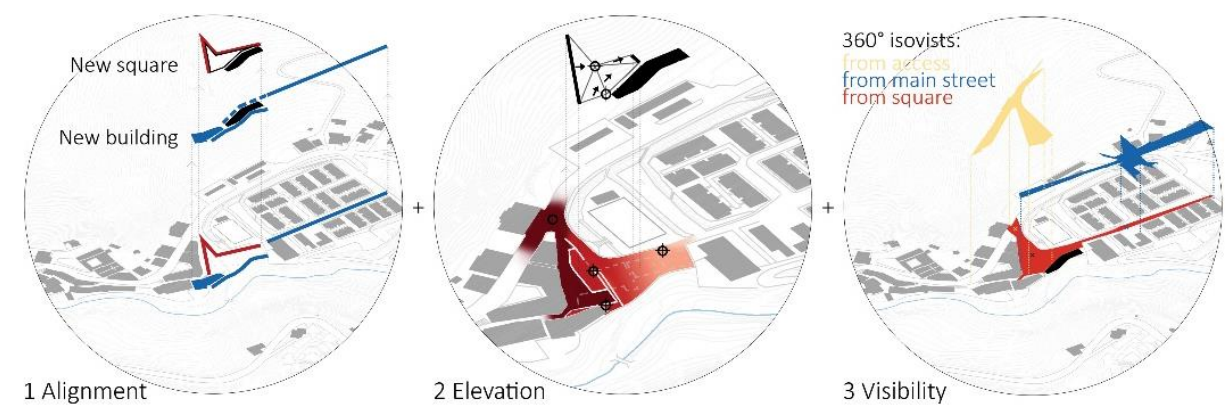

Fig. 8. Genesis of the open public space's form which is derived from: (1) boundary redefinition, (2) collimation of different elevations and (3) visual coverage.

Finally, to foster the appropriation of the public space by local communities, other complementary factors relevant to public life were considered, which translated into the design of flexible sitting spaces and public lightening (see Fig. 9). Bespoke chairs were designed to fit the particular topography of the square and to be moveable [28] and a LED lighting system was embedded in the paving of the square, following the natural movement patterns retrieved from the Space Syntax analysis at T5. In fact, by exploiting the correlations existing between the Integration index - which shows a close resemblance to actual movement levels, even in night-time - and lighting parameters $[31,32]$, it is possible to set in advance the lighting requirements. 

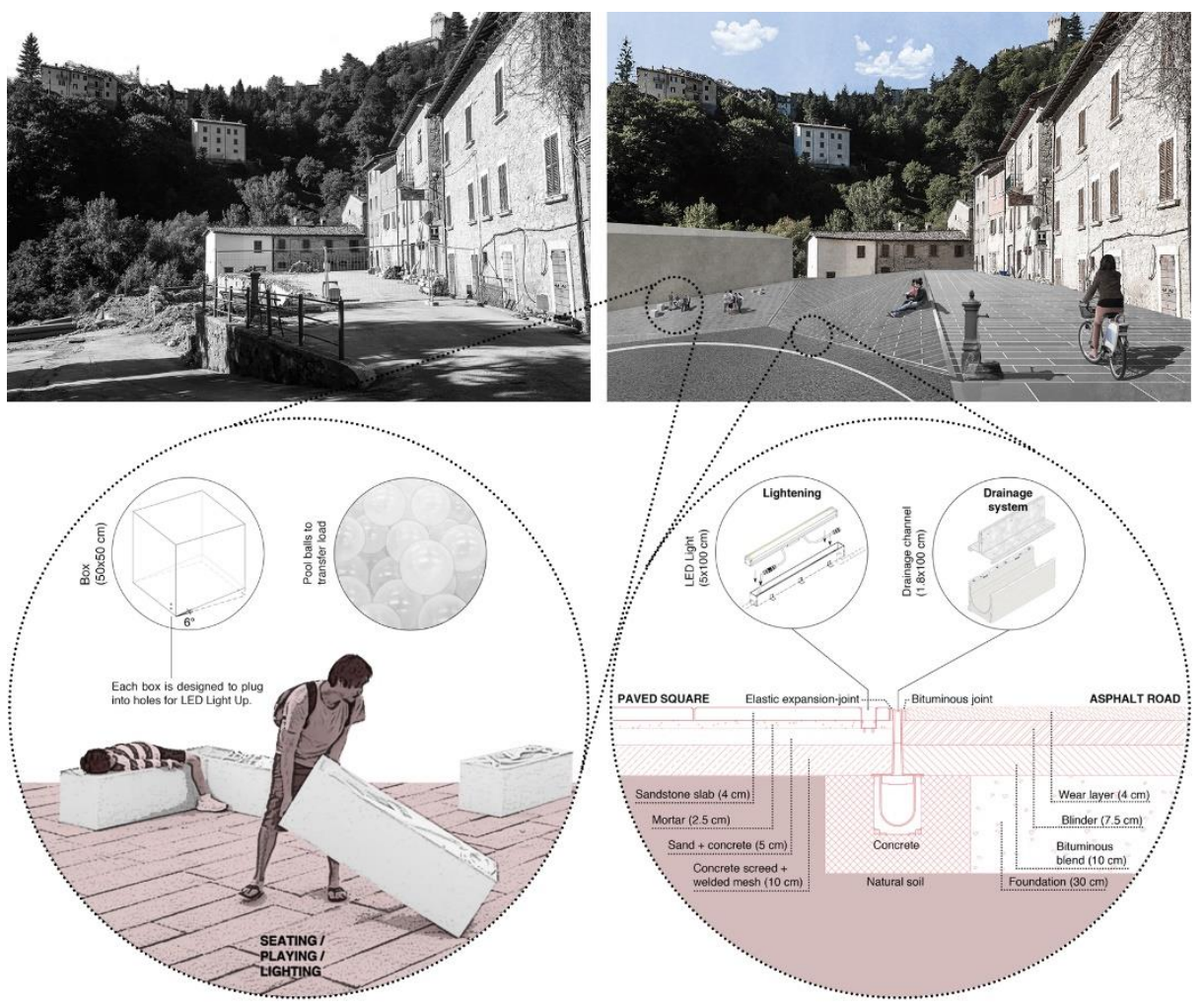

Fig. 9. View from a user perspective of the proposed design's area: as it is today (T3, left) and with the project (T5, right). In the circles, sitting spaces (left) and public lightening (right) are detailed.

To verify that all the proposed interventions were effectively planned and designed to invite the occupation of the square and to promote activities that enhance social interaction, an additional comparative design assessment was made. This helped grasping the quality of the final project in relation to the before and after configurations. The conclusive test was done using a Space Syntax Agent-based analysis, shown in Figure 10 , which generated a forecast on the patterns of movement of people in the newly designed space. The result of this analysis proved that the final design proposal will lead more people (here represented by the 'agents') inside the square. 
MOVEMENT - Gate count

T4

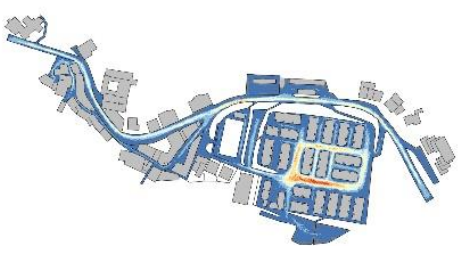

(T5)

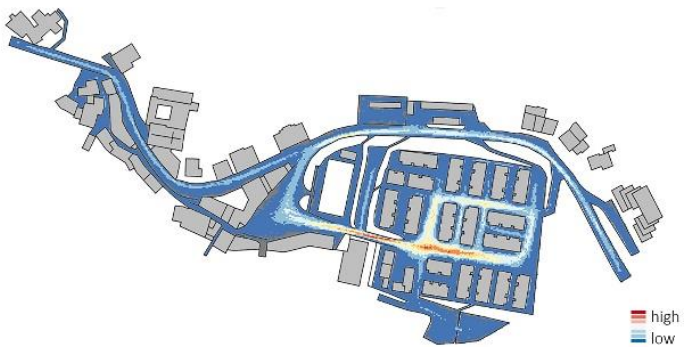

Fig. 10. Comparison between Agent-based analysis performed at two alternative future points in time: T4 (left, miniaturized) and T5 (right).

\section{Conclusions}

The present paper proved that the solution of a complex urban design problem can benefit from prior and parallel research and from the use of computational methods and tools in designing for socio-spatial performance. This approach has a good potential to effectively support strategic decision-making and to make post-disaster planning decisions more explicit, responding to a variety of challenges posed by natural hazards at different moments in time. The design workflow was presented by reporting and explaining the parameters and indices used, and by discussing possibilities of undertaking design changes when Space Syntax is part of the design decision-making process.

By illustrating the results achieved when implementing the proposed methodology in the development of a design proposal in a real case - Borgol in Arquata del Tronto - the paper showed the value of adopting a data-driven and human-centred approach to the (regenerative) design and planning of transitional urban spaces, supporting the return to a new, and possibly improved urban "normality". In fact, the analysis allowed detecting the problems and latent potentials of the site (T3), evaluating the unexpected pitfalls of the mainstream disaster reconstruction strategy (T4) and proposing an alternative plan (T5), tailored to local needs, and thus able to ensure a better performance in the short as well as in the longer run.

Future research could look at implementing the proposed approach for supporting strategic decision-making also in ordinary situations, addressing regeneration interventions; in particular, exploring the interplay between computational methods with participatory processes and community-based design for the revitalisation of small historic centres: out of post-disaster emergency, but in the long-lasting emergency due to depopulation, abandonment and decay. 


\section{References}

1. Quarantelli, E.L.: Patterns of sheltering and housing in US disasters. Disaster Prevention and Management: An International Journal 4(3), 43-53 (1995). doi: $10.1108 / 09653569510088069$

2. Johnson, C., Lizarralde, G.: Post-Disaster Housing and Reconstruction. In: Smith, S. (ed) International Encyclopaedia of Housing and Home, 340-346, Elsevier Science (2012). doi: 10.1016/B978-0-08-047163-1.00046-1

3. Ruggiero, R.: Temporary city. Between emergency and recovery. International Journal of Architecture, Art and Design, 145-152 (2018). doi: 10.19229/2464-9309/4182018

4. Alexander, D.: Preserving the Identity of Small Settlements during Post-Disaster Reconstruction in Italy. Disasters 13, 228-236 (1989). doi: 10.1111/J.14677717.1989.Tb00712.X

5. Contreras, D., Blaschke, T., Hodgson, M. E.: Lack of spatial resilience in a recovery process: Case L'Aquila, Italy. Technological Forecasting and Social Change 121, 76-88 (2017). doi: 10.1016/j.techfore.2016.12.010

6. Scamporrino, M.: Gli spazi della città in transizione nei processi di ricostruzione. In: Fabietti, V., Giannino, C., Sepe, M. (eds) La ricostruzione dopo una catastrofe: da spazio in attesa a spazio pubblico. Urbanistica online dossier 5, 35-38, INU Edizioni, Roma (2013).

7. Kennedy, J., Ashmore, J., Babister, E., Kelman, I.: The meaning of "build back better": Evidence From post-tsunami Aceh and Sri Lanka. Journal of Contingencies and Crisis Management 16(1), 24-36 (2008). doi: 10.1111/j.1468-5973.2008.00529.x

8. UNDRR: Sendai Framework for Disaster Risk Reduction 2015-2020, https://www.unisdr.org/we/coordinate/sendai-framework, last accessed 2019/05/31.

9. Jacobs, J.: The death and life of great American cities. Random House, New York (1961).

10. Chamberlain, P., Bonsiepe, G., Cross, N., Keller, I., Frens, J., Buchanan, R., Meroni, A., Krippendorff, K., Stappers, P.J., Jonas, W., Schneider, B., Vihma, S., Manzini, E.: Design Research Now: Essays and Selected Projects. Birkhäuser (2007). doi: 10.1007/978-37643-8472-2

11. Carpenter, A.: Disaster Resilience and the Social Fabric of Space. In: Proceedings of the 9th International Space Syntax Symposium. Sejong University, Seoul (2013).

12. Dipartimento della Protezione Civile: I numeri del sisma in Centro Italia (dati aggiornati al 22 agosto 2018). Modulario P.C.M. 198(3) (2018).

13. Chiappanuvoli, A.: Perché gli sfollati del terremoto sono ancora senza casa. Internazionale 31 July 2017, https://www.internazionale.it/notizie/alessandro-chiappanuvoli/2017/07/31/terremoto-case-italia-centrale, last accessed 2019/07.

14. Pezzica, C., Chioni, C., Cutini, V., Bleil de Souza, C.: Assessing the impact of temporary housing sites on urban socio-spatial performance: the case of the Central Italy earthquake. In: Proceedings of the 20th International Conference on Computational Science and Applications, Lecture Notes in Computer Science, Springer (in press).

15. Hillier, B., Hanson, J.: The Social Logic of Space. Cambridge University Press, Cambridge (2003).

16. Cutini, V.: The city, when it trembles. Earthquake destructions, post-earthquake reconstructions and grid configuration. In: Proceedings of the 9th International Space Syntax Symposium. Sejong University, Seoul (2013).

17. Pezzica, C., Cutini, V., Bleil de Souza, C.: Rapid configurational analysis using OSM data: Towards the use of Space Syntax to orient post-disaster decision making. In: Proceedings of the 12th International Space Syntax Symposium. Beijing (2019). 
18. Pezzica, C., Lopes, J.V., Paio, A.: Informed design decision-making: from digital analysis to urban design. Gestão \& Tecnologia de Projetos 12(3), 9-26 (2017). doi: 10.11606/gtp.v12i3.133936

19. Space Syntax Limited: Streets parks \& public spaces, https://spacesyntax.com/urbanplaces/streets-parks-and-public-spaces/, last accessed 2020/03/11.

20. Karimi, K.: A configurational approach to analytical urban design: 'Space syntax' methodology. URBAN DESIGN International 17(4), 297-318 (2012). doi: 10.1057/udi.2012.19

21. Lawson, B.: How designers think: the design process demystified. Butterworth Architecture, Oxford (1994).

22. Turner, A.: From Axial to Road-Centre Lines: A New Representation for Space Syntax and a New Model of Route Choice for Transport Network Analysis. Environment and Planning B: Planning and Design 34(3), 539- 555 (2007). doi: 10.1068/b32067

23. Turner, A., Doxa, M., O'Sullivan, D., Penn, A.: From Isovists to Visibility Graphs: A Methodology for the Analysis of Architectural Space. Environmental and Planning B: Planning and Design 28(1), 103-121 (2001). doi: 10.1068/b2684

24. Penn, A., Turner, A.: Space Syntax Based Agent Simulation. Presented at: 1st International Conference on Pedestrian and Evacuation Dynamics, 99-114. University of Duisburg (2001).

25. Cutini, V.: Lines and squares: towards a configurational approach to the morphology of open spaces. In: Proceedings of the 4th International Space Syntax Symposium, 49.149.14. London (2003).

26. Guerreiro, M.R., Eloy, S., Guarda, I., Lopes, P.F.: Networks and Opportunistic Urban Design: A strategy for regeneration of public spaces in Lisbon. New Urban Configurations, 766-771 (2014). doi: 10.3233/978-1-61499-365-0-771

27. Gehl, J.: Life between buildings: using public space. Danish Architectural Press, Copenhagen (2006).

28. Whyte, W.H.: The social life of small urban spaces. Project for Public Spaces, New York (2001).

29. Portoghesi, P.: La piazza come luogo degli sguardi. Gangemi, Roma (1990).

30. Sitte, C.: L'arte di costruire le città: l'urbanistica secondo i suoi fondamenti artistici. Jaca Book, Milano (1981).

31. Choi, A.-S., Kim, Y.-O., Oh, E.-S., Kim, Y.- S.: Application of the space syntax theory to quantitative street lighting design. Building and Environment 41(3), 355-366 (2006). doi: 10.1016/j.buildenv.2005.01.026

32. Leccese, F., Lista, D., Salvadori, G., Beccali, M., Bonomolo, M.: Space Syntax analysis applied to urban street lighting: relations between spatial properties and lighting levels. Applied Sciences 9(3331) (2019). doi: 10.3390/ app9163331 